OPEN ACCESS

Edited by:

Betty Diamond,

Feinstein Institute for Medical

Research, United States

Reviewed by:

Haner Direskeneli,

Marmara University, Turkey

David Saadoun,

Assistance Publique Hopitaux De

Paris (AP-HP), France

*Correspondence:

Claudia Fiorillo

claudia.fiorillo@unifi.it

†These authors have contributed equally to this work

Specialty section:

This article was submitted to Autoimmune and Autoinflammatory

Disorders,

a section of the journal

Frontiers in Immunology

Received: 19 October 2019 Accepted: 22 November 2019 Published: 13 December 2019

Citation:

Emmi G, Mannucci A, Argento FR,

Silvestri $E$, Vaglio A, Bettiol A,

Fanelli A, Stefani L, Taddei N,

Prisco D, Fiorillo $C$ and Becatti $M$ (2019) Stem-Cell-Derived Circulating Progenitors Dysfunction in Behçet's Syndrome Patients Correlates With Oxidative Stress.

Front. Immunol. 10:2877. doi: 10.3389/fimmu.2019.02877

\title{
Stem-Cell-Derived Circulating Progenitors Dysfunction in Behçet's Syndrome Patients Correlates With Oxidative Stress
}

\section{Giacomo Emmi ${ }^{1 \dagger}$, Amanda Mannucci ${ }^{2 \dagger}$, Flavia Rita Argento ${ }^{2}$, Elena Silvestri ${ }^{1}$, Augusto Vaglio ${ }^{2}$, Alessandra Bettiol ${ }^{1}$, Alessandra Fanelli ${ }^{3}$, Laura Stefani ${ }^{4}$, Niccolò Taddei ${ }^{2}$, Domenico Prisco ${ }^{1}$, Claudia Fiorillo ${ }^{2 *}$ and Matteo Becatti ${ }^{2}$}

\begin{abstract}
${ }^{1}$ Department of Experimental and Clinical Medicine, University of Firenze, Firenze, Italy, ${ }^{2}$ Department of Experimental and Clinical Biomedical Sciences "Mario Serio", University of Firenze, Firenze, Italy, ${ }^{3}$ Central Laboratory, Azienda Ospedaliero Universitaria Careggi, Firenze, Italy, ${ }^{4}$ Department of Clinical and Experimental Medicine, Center of Sports Medicine, University of Firenze, Firenze, Italy
\end{abstract}

Behçet's syndrome (BS) is a systemic vasculitis considered as the prototype of a systemic inflammation-induced thrombotic condition whose pathogenesis cannot be explained just by coagulation abnormalities. Circulating hematopoietic progenitor cells (CPC), a population of rare, pre-differentiated adult stem cells originating in the bone marrow and capable of both self-renewal and multi-lineage differentiation, are mobilized in response to vascular injury and play a key role in tissue repair. In cardiovascular and thrombotic diseases, low circulating CPC number and reduced CPC function have been observed. Oxidative stress may be one of the relevant culprits that account for the dysfunctional and numerically reduced CPC in these conditions. However, the detailed mechanisms underlying CPC number reduction are unknown. On this background, the present study was designed to evaluate for the first time the possible relationship between CPC dysfunction and oxidative stress in BS patients. In BS patients, we found signs of plasma oxidative stress and significantly lower CD34+/CD45-/dim and CD34+/CD45-/dim/CD133+ CPC levels. Importantly, in all the considered CPC subsets, significantly higher ROS levels with respect to controls were observed. Higher levels of caspase-3 activity in all the considered CPC population and a strong reduction in GSH content in CPC subpopulation from BS patients with respect to controls were also observed. Interestingly, in BS patients, ROS significantly correlated with CPC number and CPC caspase-3 activity and CPC GSH content significantly correlated with CPC number, in all CPC subsets. Collectively, these data demonstrate for the first time that CPC from BS patients show signs of oxidative stress and apoptosis and that a reduced $\mathrm{CPC}$ number is present in BS patients with respect to controls. Interestingly, we observed an inverse correlation between circulating CPC number and CPC ROS production, suggesting a possible toxic ROS effect on CPC in BS patients. The significant correlations between ROS production/GSH content and caspase-3 activity point out that oxidative 
stress can represent a determinant in the onset of apoptosis in CPC. These data support the hypothesis that oxidative-stress-mediated CPC dysfunctioning may counteract their vascular repair actions, thereby contributing to the pathogenesis and the progression of vascular disease in BS.

Keywords: Behçet's syndrome, thrombosis, circulating progenitor cells, oxidation, apoptosis

\section{INTRODUCTION}

Behçet's syndrome (BS) is a systemic vasculitis of unknown etiology characterized by muco-cutaneous and ocular manifestations as well as articular, neurological, and gastrointestinal involvements (1). Vascular involvement is also present, and represents one of the more important manifestations in terms of morbidity and mortality (2). BS affects both veins and arteries of all sizes and is usually more frequent and severe in young males (3). To date, BS may be considered as the prototype of a systemic inflammationinduced thrombotic condition. Although some studies showed different hemostatic system defects in BS $(3,4)$, current data indicate that the pathogenesis of thrombosis in BS cannot be explained by coagulation abnormalities only (5). Indeed, neutrophils are pivotal in promoting thrombo-inflammation by producing high amounts of reactive oxygen species (ROS), mainly through NADPH oxidase. This mechanism ultimately leads to a modification of the fibrin clot that becomes less susceptible to plasmin-induced lysis (6). Moreover, in BS patients, endothelial injury plays a prominent role in the onset of thrombosis and inflammation leads to thrombosis also via endothelial damage and endothelial cell dysfunction (7). Altogether, these mechanisms may partly explain why immunosuppressive treatment is essential in the management of thrombosis occurring in BS, while anticoagulation generally displays limited effects (8).

Circulating hematopoietic progenitor cells $(\mathrm{CPC})$ are a population of rare, pre-differentiated adult stem cells that originate in the bone marrow and are uniquely capable of both self-renewal and multi-lineage differentiation, including cardiomyocytes, smooth muscle cells, endothelial progenitor cells (EPC) and endothelial cells. CPC possess the ability to be mobilized in response to vascular injury and play a key role in tissue repair $(9,10)$. CPC replenish specialized somatic cells and maintain the normal turnover of regenerative tissues and organs, such as blood and skin. Interestingly, low circulating CPC number and reduced CPC function are associated with cardiovascular disease and mortality $(11,12)$.

Circulating CPC are involved in the regulation and repair of the endothelium and in vessel formation $(13,14)$. Indeed, enhanced mobilization of CPC into the blood has been associated with increased endothelial function and repair (11). However, circulating CPC number and function are dramatically altered when cardiovascular risk factors are present $(14,15)$. On the other hand, while acute inflammation increases $\mathrm{CPC}$, a chronic inflammatory state might be accompanied by a progressive CPC reduction $(16,17)$. It has been demonstrated that oxidative stress represents one of the main determinant of CPC number reduction and dysfunction in cardiovascular diseases $(18,19)$. Upon ROS production inhibition, the observed CPC alterations have been reverted $(18,19)$. However, the underlying mechanisms of CPC reduction have not been well-understood.

To date, insufficient, and conflicting clinical data to document the CPC number/function in BS patients exist $(20,21)$. Therefore, the present study was designed to evaluate for the first time the possible relationship between CPC dysfunction and oxidative stress in BS patients.

\section{MATERIALS AND METHODS}

\section{Study Population}

This was a case-control study. Sixty-one consecutive patients with BS who attended the Behçet Center of the University Hospital of Firenze, Italy, were matched 1:1 for age and sex with healthy control subjects. Patients with other autoimmune diseases and active infectious or neoplastic conditions were excluded, as well as pregnant patients. Control subjects were excluded if they had a history of cerebro- and/or cardiovascular diseases, peripheral arteriopathy, venous thrombo-embolism events, or cancer. Both patients and control subjects were assessed for the presence of vascular risk factors and drug use.

The study protocol was approved by the local Ethical Committee and informed consent was obtained from all subject enrolled.

\section{Blood Collection}

Blood samples were obtained from an antecubital vein in the morning after an overnight fasting and were collected into evacuated plastic tubes (BD Vacutainer Systems, Plymouth, UK) containing ethylenediaminetetraacetate $0.17 \mathrm{~mol} / \mathrm{L}$ for CPC evaluation.

Because inflammatory events are known to influence CPC number (16), blood was withdrawn after excluding the occurrence of infectious events, defined according to previously published criteria (22), in the previous 15 days.

\section{Flow Cytometric Analysis of CPC Oxidative Stress and Apoptosis}

CPC number was assessed by flow cytometry as previously described with minor modifications $(16,22,23)$. Briefly, $200 \mu l$ of peripheral venous blood was incubated for $20 \mathrm{~min}$ in the dark with the appropriated monoclonal antibodies (PE anti-human CD34, BD Pharmigen, Becton Dickinson, San Jose, CA; APC anti-human CD133, Miltenyi Biotec GmbH, Bergisch Gladbach, Germany; APC-Cy7 anti-human CD45 BD, Becton Dickinson, San Jose, CA). Then, $4 \mathrm{ml}$ of BD FACS Lysing Solution (Becton 
Dickinson Biosciences, San Jose, CA, USA) was added, gently mixed, and incubated at RT in the dark for $10 \mathrm{~min}$, following the manufacturer's protocol. Then, the cells were centrifuged, the supernatant was discarded, and cells were washed twice in PBS. To determine the level of intracellular ROS generation, cells were incubated with $\mathrm{H}_{2}$ DCFDA $(10 \mu \mathrm{M})$ (Invitrogen, CA, USA) in RPMI without serum and phenol red for $15 \mathrm{~min}$ at $37^{\circ} \mathrm{C}$. After labeling, cells were washed and resuspended in PBS and immediately analyzed by FACS.

To determine the level of Caspase-3 activity, single-cell suspensions were incubated in RPMI without serum and phenol red with FAM-FLICA ${ }^{\mathrm{TM}}$ Caspase-3 solution (CaspaseFLICA kit FAM-DEVD-FMK) for $30 \mathrm{~min}$ at $37^{\circ} \mathrm{C}$, following the manufacturer's protocol, and then washed twice with PBS and immediately analyzed by FACS.

To determine the level of intracellular GSH content, single-cell suspensions were incubated in RPMI without serum and phenol red with 5-chloromethylfluoresceindiacetate, CMFDA $(10 \mu \mathrm{M})$, for $30 \mathrm{~min}$ at $37^{\circ} \mathrm{C}$, washed twice with $\mathrm{PBS}$, and analyzed immediately by FACS.

A total of 300,000 cells within the leukocyte gate were acquired using a FACSCanto analyzer (Becton Dickinson, San Jose, CA). Data were processed using BD FacsDiva software. By using a modification of the International Society of Hematotherapy and Graft Engineering guidelines (24), CPC were defined as cells forming a cluster with low side scatter, low-to-intermediate CD45 staining, positive for CD34, CD133, and CD34/CD133.

\section{Protein Concentration Assay}

Protein concentration in the samples was determined using the Bradford assay (25). A standard curve of bovine serum albumin (0-15 $\mu$ g protein/200 $\mu$ l volume) was used.

\section{Protein Carbonyl Content (PC)}

Oxidative modification on plasma proteins was assessed on the basis of carbonyl content using 2-4 dinitrophenylhydrazine, as described by Levine et al. (26).

Samples were diluted to obtain a protein concentration of 10 $\mathrm{mg} / \mathrm{ml}$, and $100 \mu \mathrm{l}$ of each sample was aliquoted in Eppendorf tubes. For each sample, a blank measurement was prepared. Then, $400 \mu \mathrm{l}$ of a DNPH solution $(5 \mathrm{mM}$ in $2.5 \mathrm{M} \mathrm{HCl})$ was added to tubes. Blank tubes were also prepared, adding the $\mathrm{HCl}$ solution without DNPH. Then, all the tubes were incubated in the dark for an hour, vortexing every 15-20 min. After incubation, protein content was precipitated by adding $500 \mu \mathrm{l}$ of a $20 \%$ trichloroacetic acid (TCA) solution, placing tubes on ice for $5 \mathrm{~min}$, and centrifuging at $10,000 \mathrm{~g}$ for $5 \mathrm{~min}$ to pellet protein content. The supernatant was discarded and the pellet was washed once with $500 \mu \mathrm{l}$ of $10 \% \mathrm{TCA}$, and then twice with $500 \mu \mathrm{l}$ of a 1:1 solution of ethanol-ethyl acetate. Finally, the pellet was resuspended in guanidine hydrochloride at $37^{\circ} \mathrm{C}$ for $15 \mathrm{~min}$ and the absorbance of carbonyl-bound DNPH was read at $370 \mathrm{~nm}$. The corrected absorbance was calculated subtracting the mean of blank values from raw DNPH values. Then, the concentration was determined using an extinction coefficient of $0.022 \mu \mathrm{M}^{-1}$ $\mathrm{cm}^{-1}$, and normalized with the total protein content.

\section{TBARS (Thiobarbituric Acid Reactive Substances) Estimation}

Plasma TBARS levels were measured using a TBARS assay kit (OXI-TEK, ENZO, USA) as previously reported (27). Briefly, the adduct generated by reacting malondialdehyde with thiobarbituric acid after $1 \mathrm{~h}$ at $95^{\circ} \mathrm{C}$ was measured spectrofluorimetrically, with excitation at $530 \mathrm{~nm}$ and emission at $550 \mathrm{~nm}$. TBARS were expressed in terms of malondialdehyde equivalent $(\mathrm{nmol} / \mathrm{ml})$ and then normalized for protein concentration.

\section{Total Antioxidant Capacity (TAC) Assay}

The ORAC method (oxygen radical absorbance capacity) was performed as previously described on plasma samples (28). Briefly, fluorescein solution $(6 \mathrm{nM})$ was prepared daily in $75 \mathrm{mM}$ sodium phosphate buffer ( $\mathrm{pH} 7.4)$ and Trolox $(250 \mu \mathrm{M}$ final concentration) was used as a standard. Seventy microliters of each sample with $100 \mu \mathrm{l}$ of fluorescein was pre-incubated for $30 \mathrm{~min}$ at $37^{\circ} \mathrm{C}$ in each well, before rapidly adding AAPH solution (19 mM final concentration). Fluorescence was measured using Synergy H1 microplate reader (BioTek, Winooski, VT). Results were expressed as Trolox Equivalents $(\mu \mathrm{M})$ and then normalized for protein concentration.

\section{Statistical Analysis}

To assess the statistical significance of differences in clinical data and progenitor cell numbers between patients with BS and control subjects, the $\chi^{2}$ test for categorical variables and Mann-Whitney test for numeric variables were used. Logistic regression analysis, including age, drug use, and sex as variables possibly influencing the cell number, was performed to test the independency of associations. In this analysis, the logarithm of the cell number was used for a better evaluation of the OR. All analyses were performed using the SPSS (Statistical Package for Social Sciences, Chicago, IL) software for Windows (Version 15.0).

\section{RESULTS}

All the patients enrolled in the study fulfilled the International Criteria for Behçet Disease (ICBD) (29). At the beginning of the disease, almost all the patients presented oral ulcers (96.7\%), followed by cutaneous and articular involvement (65.6 and 59\%, respectively). More than one third of the patients also had ocular and intestinal manifestations, as well as genital ulcers and vascular involvement. HLA-B51 was present in $42.6 \%$ of the patients.

All the patients with a Behçet Disease Activity Form (BDCAF) with a score $\geq 1$ were considered active, while BS patients with a BDCAF equal to 0 were defined inactive.

Only a minority of the patients had no treatment at the time of the enrollment or were on corticosteroid as the unique therapy (11.5 and 4.9\%, respectively). The majority of the BS patients were on Disease Modifying Anti Rheumatic Drugs (DMARDs) (32.8\%) or on biologic +/- traditional DMARDs (50.8\%).

Demographic and clinical features of the population studied are summarized in detail in Table $\mathbf{1}$. 
TABLE 1 | Main clinical and demographic features of the patients enrolled in the study.

\begin{tabular}{|c|c|}
\hline & $N(\%$ out of 61$)$ \\
\hline$N$ obs & 61 \\
\hline \multicolumn{2}{|l|}{ Sex } \\
\hline Male & $32(52.5)$ \\
\hline Female & $29(47.5)$ \\
\hline \multicolumn{2}{|l|}{ Age at diagnosis } \\
\hline Median (IQR; range) & $35(26-42)$ \\
\hline \multicolumn{2}{|l|}{ HLA-B51 } \\
\hline Positive & $26(42.6)$ \\
\hline \multicolumn{2}{|c|}{ Manifestations at baseline (ICBD criteria) } \\
\hline Oral aphthosis & $59(96.7)$ \\
\hline Skin involvement & $40(65.6)$ \\
\hline Articular involvement & $36(59.0)$ \\
\hline Ocular involvement & $23(37.7)$ \\
\hline Intestinal involvement & $22(36.1)$ \\
\hline Genital aphthosis & $21(34.4)$ \\
\hline Vascular involvement & $20(32.8)$ \\
\hline Neurologic involvement & $17(27.9)$ \\
\hline Positive pathergy test & $4(6.6)$ \\
\hline \multicolumn{2}{|c|}{ Disease activity at time of sample collection } \\
\hline Not active $(\mathrm{BDCAF}=0)$ & $21(34.4)$ \\
\hline Active $(\mathrm{BDCAF} \geq 1)$ & $40(65.6)$ \\
\hline \multicolumn{2}{|c|}{ Active manifestations at time of sample collection } \\
\hline Oral aphthosis & $22(36.1)$ \\
\hline Articular involvement & $17(27.9)$ \\
\hline Intestinal involvement & $11(18.0)$ \\
\hline Skin involvement & $10(16.4)$ \\
\hline Ocular involvement & $9(14.8)$ \\
\hline Neurologic involvement & $5(8.2)$ \\
\hline Vascular involvement & $4(6.6)$ \\
\hline Genital aphthosis & $1(1.6)$ \\
\hline \multicolumn{2}{|c|}{ Ongoing pharmacological therapies } \\
\hline No treatment & $7(11.5)$ \\
\hline Only corticosteroids & $3(4.9)$ \\
\hline Traditional DMARDs & $20(32.8)$ \\
\hline Biologic ( \pm traditional) DMARDs & $31(50.8)$ \\
\hline
\end{tabular}

\section{Plasma Oxidative Stress}

As reported in Table 2, patient plasma displayed significantly higher total PC and TBARS levels compared to healthy controls $(p<0.0001$ vs. controls).

\section{Levels of Circulating Progenitor Cells}

Because several CPC may participate to vascular repair, different phenotypically defined subpopulations of $\mathrm{CD} 34+$ CPC were analyzed by FACS analysis, allowing one to determine the level of overall $\mathrm{CD} 34+/ \mathrm{CD} 45^{-/ \mathrm{dim}}$ $\mathrm{CPC}$, of $\mathrm{CD} 34+/ \mathrm{CD} 45^{-/ \mathrm{dim}} / \mathrm{CD} 133-\mathrm{CPC}$, and of $\mathrm{CD} 34+/ \mathrm{CD} 45^{-/ \mathrm{dim}} / \mathrm{CD} 133+$, representative of more immature CPC. As summarized in Figure 1A, significantly lower $\mathrm{CD} 34+/ \mathrm{CD} 45^{-/ \mathrm{dim}}$ and $\mathrm{CD} 34+/ \mathrm{CD} 45^{-/ \mathrm{dim} / \mathrm{CD} 133+\mathrm{CPC}}$
TABLE 2 | Oxidative stress markers.

\begin{tabular}{lccc}
\hline & $\begin{array}{c}\text { Controls } \\
\boldsymbol{n}=\mathbf{6 1}\end{array}$ & $\begin{array}{c}\text { BS patients } \\
\boldsymbol{n}=\mathbf{6 1}\end{array}$ & \\
\hline Plasma PC (nmol/mg) & $10.87 \pm 3.08$ & $17.75 \pm 4.18$ & $p<0.0001$ \\
Plasma TBARS (nmol/ml) & $0.66 \pm 0.11$ & $2.21 \pm 0.82$ & $p<0.0001$ \\
Plasma TAC (nmol Trolox & $21.8 \pm 3.9$ & $15.2 \pm 4.8$ & $p<0.0001$ \\
equivalent/mg of protein) & & & \\
\hline
\end{tabular}

levels were observed in BS patients with respect to controls (245 \pm 92 vs. $637 \pm 96, p<0.0001 ; 80 \pm 28$ vs. $536 \pm 88, p<0.0001$, respectively). On the contrary, $\mathrm{CD} 34+/ \mathrm{CD} 45^{-/ \mathrm{dim}} / \mathrm{CD} 133-$ level was significantly higher $(p<0.0001)$ in BS patients with respect to controls ( $165 \pm 70$ vs. $101 \pm 26)$.

\section{CPC Oxidative Stress and Apoptosis}

As shown in Figure 1B, in all the considered CPC subsets, we observed significantly higher $(p<0.0001)$ ROS levels in BS patients with respect to controls $\left(\mathrm{CD} 34+/ \mathrm{CD} 45^{-/ \mathrm{dim}}: 14,333\right.$

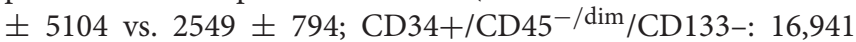
\pm 7444 vs. $4728 \pm 2165 ; \mathrm{CD} 34+/ \mathrm{CD} 45^{-/ \mathrm{dim}} / \mathrm{CD} 133+: 10,396$ \pm 3469 vs. $2169 \pm 737$ ). Likewise, as shown in Figure 1C, we observed significantly higher levels of caspase-3 activity $(p<$ 0.0001) in all the considered CPC population in BS patients with respect to controls $\left(\mathrm{CD} 34+/ \mathrm{CD} 45^{-/ \mathrm{dim}}: 8704 \pm 3158\right.$ vs. 323

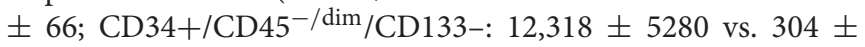
73; $\mathrm{CD} 34+/ \mathrm{CD} 45^{-/ \mathrm{dim}} / \mathrm{CD} 133+: 2197 \pm 1002$ vs. $3274 \pm 67$ ). A strong reduction in GSH content (Figure 1D) in the CPC subpopulation from BS patients with respect to controls was observed $\left(\mathrm{CD} 34+/ \mathrm{CD} 45^{-/ \mathrm{dim}}: 8454 \pm 1874\right.$ vs. $64,792 \pm 7825$; CD34+/CD45-/dim/CD133-: $3993 \pm 1407$ vs. $48,943 \pm 7764$; CD34+/CD45-/dim/CD133+: 17,598 \pm 5101 vs. $67,828 \pm 8206)$.

\section{Correlation Between Investigated Parameters}

As shown in Figure 2A, in all the considered CPC subsets, ROS significantly correlated with CPC number. At the same time, CPC caspase- 3 activity (Figure 2B) and CPC GSH content (Figure 2C) significantly correlated with CPC number, in all CPC subsets.

\section{DISCUSSION}

BS is considered the prototype of systemic inflammatory disease causing thrombosis, but the mechanisms underlying the relationship between inflammation and vascular events are far to be elucidated.

In this study, we investigated in a cohort of Behçet's patients the role of CPC, a population of undifferentiated progenitor cells originated in the bone marrow with the ability to be mobilized in response to vascular injury and capable of multi-lineage differentiation including EPC and endothelial cells.

Both EPC and CPC are considered surrogate biomarkers of cardiovascular health since they appear to constitute a natural system for the maintenance of vascular function, improving endothelial repair and neovascularization (30-32). Notably, 


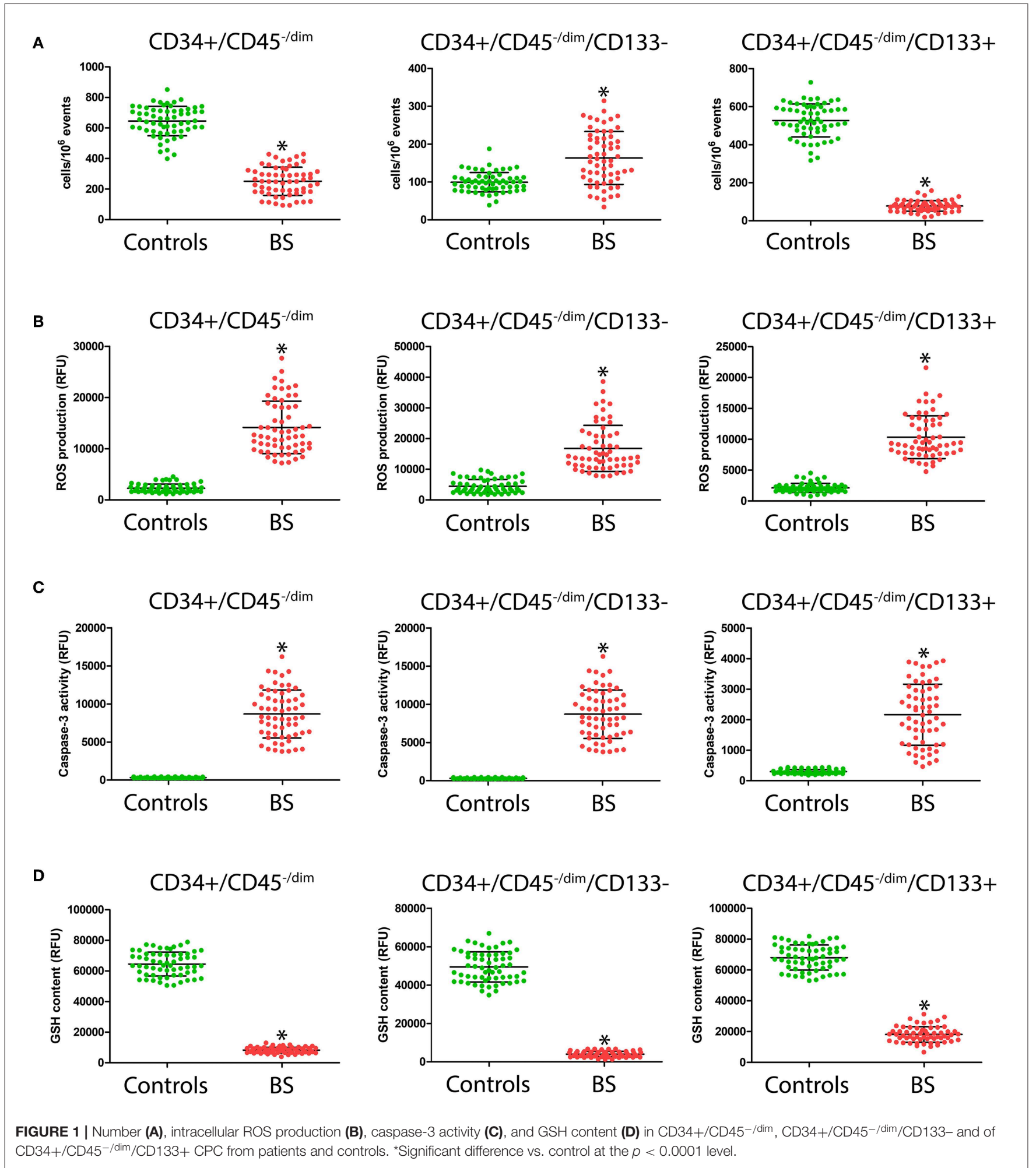

the restoration of blood supply to ischemic tissues is strictly dependent on endothelial regeneration and angiogenesis. Here, we demonstrate for the first time that CPC from BS patients, but not those from healthy subjects, show signs of oxidative stress and apoptosis. Another important finding emerging from our study is the reduced CPC number observed in BS patients with respect to control subjects. Importantly, the number and function of CPC may reflect the balance between endothelial integrity and repair 
A

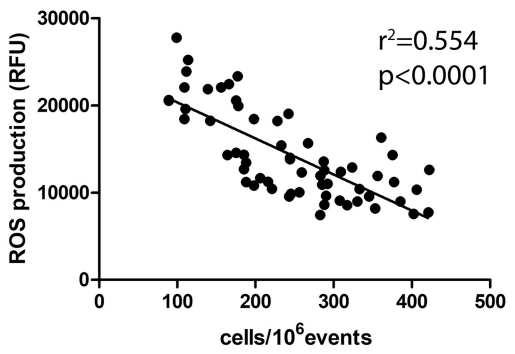

B

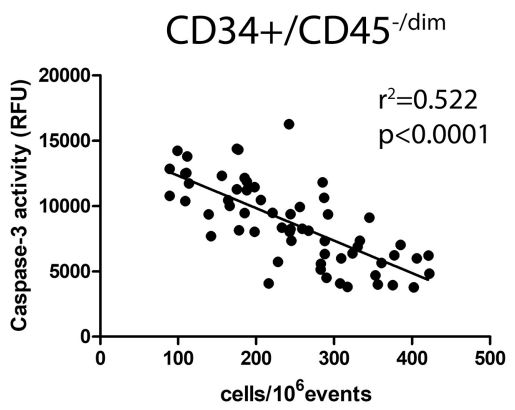

C

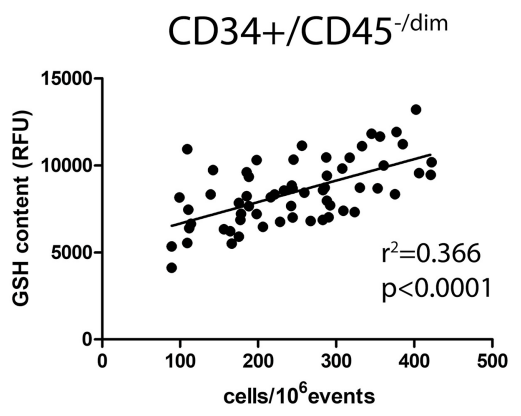

CD34+/CD45-/dim/CD133-

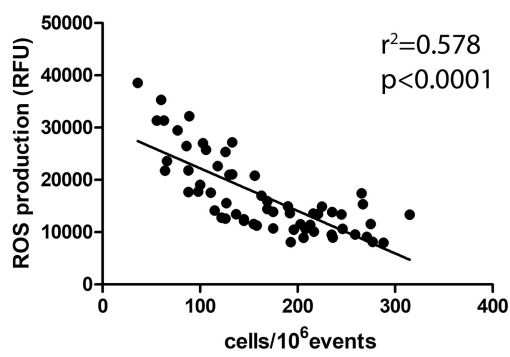

CD34+/CD45-/dim/CD133-

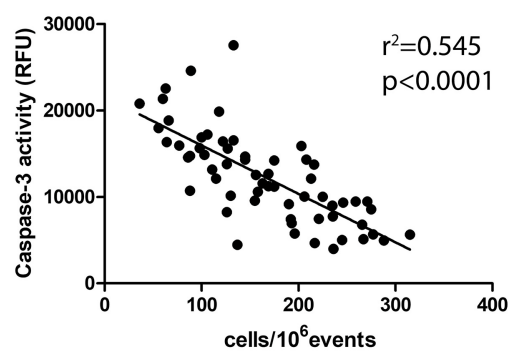

CD34+/CD45-/dim/CD133-

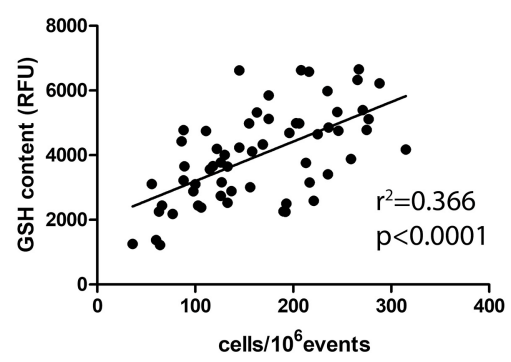

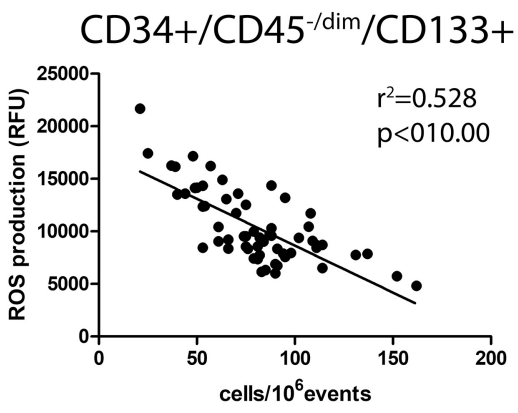

CD34+/CD45-/dim/CD133+

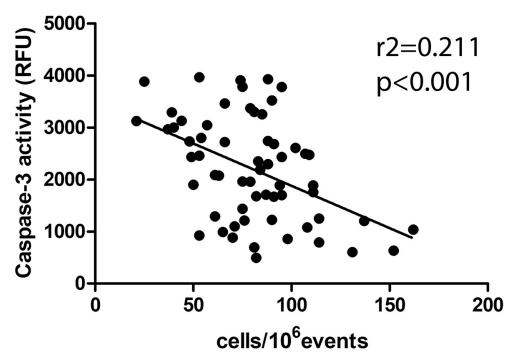

CD34+/CD45-/dim/CD133+

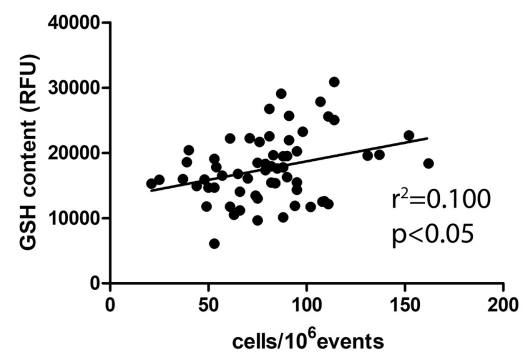

FIGURE 2 | Correlation analysis among CPC number and intracellular ROS production (A), caspase-3 activity (B), and GSH content (C).

and can be used as a marker of endothelial function. Indeed, patients with hypertension, coronary artery disease, chronic renal failure, diabetes, sepsis, and rheumatoid arthritis exhibit decreased CPC number (33-36). Moreover, EPC isolated from patients with coronary artery disease and hypertension display an impaired migratory response $(34,35)$.

The decline in CPC number can be attributed to increased apoptosis, oxidative stress, inflammation, and senescence, in addition to reduced growth and migration from bone marrow (33). However, recent data suggest that increased CPC number may also represent a homoeostatic stress response contributing to vascular damage repair $(36,37)$. Indeed, in acute coronary syndromes, the early CPC mobilization from the bone marrow seems related to the extension of myocardial ischemia expressed as area at risk (38) and may contribute to the healing process by promoting neovascularization (39).

Moreover, we observed an inverse correlation between circulating CPC number and CPC ROS production, suggesting a possible toxic ROS effect on CPC in BS patients. Indeed, signs of oxidative stress (increased ROS production and reduced GSH content) and apoptosis in CPC from BS patients were observed, suggesting a functional impairment of these cells. Furthermore, the significant correlations between ROS production/GSH content and caspase- 3 activity point out that oxidative stress can represent a determinant in the onset of apoptosis in CPC.

To date, few data are available about the possible pathogenetic role of CPC in systemic vasculitis. It was previously reported that the increased number of circulating inflammatory endothelial cells could represent an activity marker in patients with systemic necrotizing vasculitis (40). EPC were reported to be increased in number also in a patient with BS complicated with cerebral trombophlebitis (41). Recently, Bozkirli et al. demonstrated that EPC number was significantly higher in BS patients with thrombosis (42). On the other hand, it was also demonstrated that BS is associated with a progressive reduction in EPC number, which can be interpreted as a mechanism of induction and/or 
progression of vascular injury in these patients (21). However, to date, there are no data on CPC function in BS patients.

In the case of EPC population, the univocal interpretation of data is limited by the extremely low frequency of the analyzed cell populations and by the lack of validation of the utilized markers. For this reason, in this study, we analyzed the most abundant CPC population instead of the rare EPC population (which accounts for about $0.01-0.0001 \%$ of nucleated cells). To our knowledge, this is the first study to detect ROS production, GSH content, and caspase- 3 activation in CPC, defined as CD $34+/ C D 45^{-/ \text {low }} / \mathrm{CD} 133+$ and CD34+/CD $45^{-/ \text {low }} / \mathrm{CD} 133-$, in peripheral blood (not in isolated and cultured cells).

It is accepted that EPC mobilization can be stimulated by transient restricted inflammatory response, while highgrade inflammation results in decreased EPC number and EPC dysfunction (43). Considerable evidence also suggests that ROS play a key role in EPC mobilization/function (44). In particular, low ROS levels activate pro-angiogenic pathways in EPC, whereas high ROS levels impair EPC function. Therefore, oxidative stress is responsible not only for EPC circulating number reduction but also for an impairment EPC function with consequent harmful effects in vascular homeostasis. Indeed, during conditions such as diabetes mellitus, characterized by oxidative stress, the mobilization of dysfunctional EPC is observed (45). Indeed, increased superoxide generation reduces EPC levels and impairs EPC function (46). In addition, incubation of EPC with hydrogen peroxide has been shown to induce apoptosis (47), profoundly reducing EPC number (48). Furthermore, increased ROS production has been associated with reduced EPC levels in a rat model of myocardial infarction (49).

An overall imbalance in blood redox status has been proposed in BS (50). Recently, we demonstrated that neutrophils are responsible for an increased ROS production in BS patients, thus favoring thrombosis through a deep modification of fibrinogen secondary structure (51). Accordingly, in the present study, plasma protein carbonyls and TBARS were markedly and significantly increased in BS patients when compared with control subjects, thus confirming an altered oxidative status in BS patients.

In human vasculature, ROS production is counterbalanced by several antioxidant molecules aimed at ROS scavenging. Intracellular antioxidant enzymes, such as glutathione peroxidase, catalase, and manganese superoxide dismutase, were increased in EPC from healthy subjects with respect to differentiated, mature endothelial cells (52). This is in agreement with our data that show, for the first time, a marked increase $(+62 \%)$ in ROS production in CD133population with respect to the more immature CD133+ population, in human peripheral blood. In addition, our results indicate, in CPC from human peripheral blood, a significant reduction in GSH content compared with $\mathrm{CPC}$ from control subjects, suggesting that an impairment in antioxidant system can promote CPC sensitivity toward oxidative-stress-mediated apoptosis and consequently reduced CPC number in BS patients. Our observations were supported by the finding that glutathione peroxidase-1-deficient mice exhibited a reduced number and functional activity of progenitor cells (53).

The exact oxidative mechanisms underlying CPC dysfunction has not yet been understood. To date, no study has addressed the question whether redox balancing therapeutic strategies can modify CPC function and number. Only when antioxidant therapies will demonstrate to improve these parameters of CPC biology will a safe conclusion be drawn regarding ROS and CPC relationship in humans.

The results of the present study may have implications in the pathogenesis of thrombotic manifestations in BS. Indeed, CPC have not only been associated with coronary artery disease (54) and atherosclerosis (55). Different from other inflammatory immune-mediated conditions, BS is not associated with accelerated atherosclerosis, despite without having a clear pathogenetic explanation (56). Notably, CPC dysfunction has been also evoked as a potential mechanism in deep vein thrombosis occurrence (57) and aneurysm formation (58), typical clinical features of BS.

Future longitudinal studies on a larger BS population would be helpful in order to explore CPC dysfunction in specific subsets of BS patients. Moreover, functional analysis showing the impact of ROS production on vessel wall of BS patients would be of importance.

However, taking into account that oxidative stress plays an important role in the pathogenesis of all vascular diseases (59), our data support the hypothesis that oxidative-stress-mediated $\mathrm{CPC}$ dysfunctioning may counteract their vascular repair actions, thereby contributing to the pathogenesis and the progression of vascular disease in BS patients.

\section{DATA AVAILABILITY STATEMENT}

The datasets generated for this study are available on request to the corresponding author.

\section{ETHICS STATEMENT}

The studies involving human participants were reviewed and approved by Comitato Etico Università degli Studi di Firenze, Largo Brambilla 3, Firenze, Italy. The patients/participants provided their written informed consent to participate in this study.

\section{AUTHOR CONTRIBUTIONS}

GE, AM, FA, ES, AB, CF, and $\mathrm{MB}$ were responsible for data collection and analysis. $\mathrm{MB}, \mathrm{AM}$, and FA performed experiments. GE, ES, AV, and DP monitored patient inclusion. $\mathrm{MB}$ and $\mathrm{CF}$ were responsible for protocol development and study funding, and supervised the study. NT, AF, and LS gave critical guidance during the project. $\mathrm{MB}, \mathrm{GE}$, and $\mathrm{CF}$ designed the experiments and wrote the manuscript. All authors contributed substantially to the critical revision of the manuscript, and gave approval of the final draft. 


\section{FUNDING}

This study was supported by Fondazione CR Firenze research funding no. 0849.2017 attributed to $\mathrm{MB}$ and by

\section{REFERENCES}

1. Leccese P, Alpsoy E. Behçet's disease: an overview of etiopathogenesis. Front Immunol. (2019) 10:1067. doi: 10.3389/fimmu.2019.01067

2. Emmi G, Bettiol A, Silvestri E, Di Scala G, Becatti M, Fiorillo C, et al. Vascular Behçet's syndrome: an update. Intern Emerg Med. (2019) 14:645-52. doi: 10.1007/s11739-018-1991-y

3. Emmi G, Silvestri E, Squatrito D, Amedei A, Niccolai E, D’Elios MM, et al. Thrombosis in vasculitis: from pathogenesis to treatment. Thromb J. (2015) 13:15. doi: 10.1186/s12959-015-0047-z

4. Espinosa G, Font J, Tàssies D, Vidaller A, Deulofeu R, López-Soto A, et al. Vascular involvement in Behçet's disease: relation with thrombophilic factors, coagulation activation, and thrombomodulin. Am J Med. (2002) 112:37-43. doi: 10.1016/S0002-9343(01)01048-8

5. Becatti M, Emmi G, Bettiol A, Silvestri E, Di Scala G, Taddei N, et al. Behçet's syndrome as a tool to dissect the mechanisms of thrombo-inflammation: clinical and pathogenetic aspects. Clin Exp Immunol. (2019) 195:322-33. doi: 10.1111/cei.13243

6. Emmi G, Becatti M, Bettiol A, Hatemi G, Prisco D, Fiorillo C. Behçet's syndrome as a model of thrombo-inflammation: the role of neutrophils. Front Immunol. (2019) 10:1085. doi: 10.3389/fimmu.2019.01085

7. Butta NV, Fernández-Bello I, López-Longo FJ, Jiménez-Yuste V. Endothelial dysfunction and altered coagulation as mediators of thromboembolism in behçet disease. Semin Thromb Hemost. (2015) 41:621-8. doi: 10.1055/s-0035-1556727

8. Hatemi G, Christensen R, Bang D, Bodaghi B, Celik AF, Fortune F, et al. 2018 update of the EULAR recommendations for the management of Behçet's syndrome. Ann Rheum Dis. (2018) 77:808-18. doi: 10.1136/annrheumdis-2018-213225

9. Weissman IL. Stem cells: units of development, units of regeneration, and units in evolution. Cell. (2000) 100:157-68. doi: 10.1016/S0092-8674(00)81692-X

10. Mazo IB, Massberg S, von Andrian UH. Hematopoietic stem and progenitor cell trafficking. Trends Immunol. (2011) 32:493-503. doi: 10.1016/j.it.2011.06.011

11. Foresta C, De Toni L, Ferlin A, Di Mambro A. Clinical implication of endothelial progenitor cells. Expert Rev Mol Diagn. (2010) 10:89-105. doi: 10.1586/erm.09.80

12. Sen S, McDonald SP, Coates PT, Bonder CS. Endothelial progenitor cells: novel biomarker and promising cell therapy for cardiovascular disease. Clin Sci. (2011) 120:263-83. doi: 10.1042/CS20100429

13. Lamping K. Endothelial progenitor cells: sowing the seeds for vascular repair. Circ Res. (2007) 100:1243-5. doi: 10.1161/01.RES.0000268193.46418.d1

14. Giannotti G, Doerries C, Mocharla PS, Mueller MF, Bahlmann FH, Horvàth T, et al. Impaired endothelial repair capacity of early endothelial progenitor cells in prehypertension: relation to endothelial dysfunction. Hypertension. (2010) 55:1389-97. doi: 10.1161/HYPERTENSIONAHA.109.141614

15. Marrotte EJ, Chen DD, Hakim JS, Chen AF. Manganese superoxide dismutase expression in endothelial progenitor cells accelerates wound healing in diabetic mice. J Clin Invest. (2010) 120:4207-19. doi: 10.1172/JCI36858

16. Cesari F, Caporale R, Marcucci R, Caciolli S, Stefano PL, Capalbo A, et al. NTproBNP and the anti-inflammatory cytokines are correlated with endothelial progenitor cells' response to cardiac surgery. Atherosclerosis. (2008) 199:13846. doi: 10.1016/j.atherosclerosis.2007.09.045

17. Fujii H, Li SH, Szmitko PE, Fedak PW, Verma S. C-reactive protein alters antioxidant defenses and promotes apoptosis in endothelial progenitor cells. Arterioscler Thromb Vasc Biol. (2006) 26:2476-82. doi: 10.1161/01.ATV.0000242794.65541.02

18. Chen DD, Dong YG, Yuan H, Chen AF. Endothelin 1 activation of endothelin A receptor/NADPH oxidase pathway and diminished
Fondi di Ateneo research funding from the University of Florence to GE. This study was also partly supported by the Associazione Italiana Sindrome e Malattia di Behçet (SIMBA). antioxidants critically contribute to endothelial progenitor cell reduction and dysfunction in salt-sensitive hypertension. Hypertension. (2012) 59:1037-43. doi: 10.1161/HYPERTENSIONAHA.111.183368

19. Ceradini DJ, Yao D, Grogan RH, Callaghan MJ, Edelstein D, Brownlee M, et al. Decreasing intracellular superoxide corrects defective ischemia-induced new vessel formation in diabetic mice. J Biol Chem. (2008) 283:10930-8. doi: 10.1074/jbc.M707451200

20. Bozkirli ED, Keșkek SÖ, Kozanoglu I, Yücel AE. High levels of endothelia progenitor cells can be associated with thrombosis in patients with Behçet's disease. Clin Exp Rheumatol. (2014) 32(4 Suppl. 84):S49-53.

21. Fadini GP, Tognon S, Rodriguez L, Boscaro E, Baesso I, Avogaro A, et al. Low levels of endothelial progenitor cells correlate with disease duration and activity in patients with Behçet's disease. Clin Exp Rheumatol. (2009) 27:814-21

22. Nencini P, Sarti C, Innocenti R, Pracucci G, Inzitari D. Acute inflammatory events and ischemic stroke subtypes. Cerebrovasc Dis. (2003) 15:215-21. doi: 10.1159/000068831

23. Cesari F, Sofi F, Caporale R, Capalbo A, Marcucci R, Macchi C, et al. Relationship between exercise capacity, endothelial progenitor cells and cytochemokines in patients undergoing cardiac rehabilitation. Thromb Haemost. (2009) 101:521-6. doi: 10.1160/TH08-10-0644

24. Sutherland DR, Anderson L, Keeney M, Nayar R, Chin-Yee I. The ISHAGE guidelines for CD34+ cell determination by flow cytometry. International society of hematotherapy and graft engineering. J Hematother. (1996) 5:21326. doi: 10.1089/scd.1.1996.5.213

25. Bradford MM. A rapid and sensitive method for the quantitation of microgram quantities of protein utilizing the principle of protein-dye binding. Anal Biochem. (1976) 72:248-54. doi: 10.1006/abio.1976.9999

26. Levine RL, Williams JA, Stadtman ER, Shacter E. Carbonyl assays for determination of oxidatively modified proteins. Methods Enzymol. (1994) 233:346-57. doi: 10.1016/S0076-6879(94)33040-9

27. Fiorillo C, Becatti M, Attanasio M, Lucarini L, Nassi N, Evangelisti L, et al. Evidence for oxidative stress in plasma of patients with Marfan syndrome. Int J Cardiol. (2010) 145:544-6. doi: 10.1016/j.ijcard.2010.04.077

28. Sofi F, Dinu M, Pagliai G, Cesari F, Gori AM, Sereni A, et al Low-calorie vegetarian versus mediterranean diets for reducing body weight and improving cardiovascular risk profile: CARDIVEG study (Cardiovascular Prevention With Vegetarian Diet). Circulation. (2018) 137:1103-13. doi: 10.1161/CIRCULATIONAHA.117.030088

29. International Team for the Revision of the International Criteria for Behçet's Disease (ITR-ICBD). The international criteria for Behçet's disease (ICBD): a collaborative study of 27 countries on the sensitivity and specificity of the new criteria. J Eur Acad Dermatol Venereol. (2014) 28:338-47. doi: $10.1111 /$ jdv.12107

30. Bianconi V, Sahebkar A, Kovanen P, Bagaglia F, Ricciuti B, Calabrò P, et al. Endothelial and cardiac progenitor cells for cardiovascular repair: a controversial paradigm in cell therapy. Pharmacol Ther. (2018) 181:156-68. doi: 10.1016/j.pharmthera.2017.08.004

31. Rigato M, Fadini GP. Circulating stem/progenitor cells as prognostic biomarkers in macro- and microvascular disease: a narrative review of prospective observational studies. Curr Med Chem. (2018) 25:4507-17. doi: 10.2174/0929867324666170920154020

32. Cesari F, Sofi F, Molino Lova R, Vannetti F, Pasquini G, Cecchi F, et al. Aging process, adherence to Mediterranean diet and nutritional status in a large cohort of nonagenarians: effects on endothelial progenitor cells. Nutr Metab Cardiovasc Dis. (2018) 28:84-90. doi: 10.1016/j.numecd.2017. 09.003

33. Umemura T, Higashi Y. Endothelial progenitor cells: therapeutic target for cardiovascular diseases. J Pharmacol Sci. (2008) 108:1-6. doi: 10.1254/jphs.08R01CP 
34. Vasa M, Fichtlscherer S, Aicher A, Adler K, Urbich C, Martin H, et al. Number and migratory activity of circulating endothelial progenitor cells inversely correlate with risk factors for coronary artery disease. Circ Res. (2001) 89:E1-7. doi: 10.1161/hh1301.093953

35. Vasa M, Fichtlscherer S, Adler K, Aicher A, Martin H, Zeiher AM, et al. Increase in circulating endothelial progenitor cells by statin therapy in patients with stable coronary artery disease. Circulation. (2001) 103:2885-90. doi: 10.1161/hc2401.092816

36. Grisar J, Aletaha D, Steiner CW, Kapral T, Steiner S, Seidinger D, et al. Depletion of endothelial progenitor cells in the peripheral blood of patients with rheumatoid arthritis. Circulation. (2005) 111:204-11. doi: 10.1161/01.CIR.0000151875.21836.AE

37. Valgimigli M, Rigolin GM, Fucili A, Porta MD, Soukhomovskaia O, Malagutti P, et al. CD34+ and endothelial progenitor cells in patients with various degrees of congestive heart failure. Circulation. (2004) 110:1209-12. doi: 10.1161/01.CIR.0000136813.89036.21

38. Porto I, Leone AM, De Maria GL, Hamilton Craig C, Tritarelli A, Camaioni $\mathrm{C}$, et al. Are endothelial progenitor cells mobilized by myocardial ischemia or myocardial necrosis? A cardiac magnetic resonance study. Atherosclerosis. (2011) 216:355-8. doi: 10.1016/j.atherosclerosis.2011. 02.014

39. Dubois C, Liu X, Claus P, Marsboom G, Pokreisz P, Vandenwijngaert $\mathrm{S}$, et al. Differential effects of progenitor cell populations on left ventricular remodeling and myocardial neovascularization after myocardial infarction. J Am Coll Cardiol. (2010) 55:2232-43. doi: 10.1016/j.jacc.2009. 10.081

40. Hergesell O, Andrassy K, Nawroth P. Elevated levels of markers of endothelial cell damage and markers of activated coagulation in patients with systemic necrotizing vasculitis. Thromb Haemost. (1996) 75:892-8. doi: 10.1055/s-0038-1650390

41. Camoin-Jau L, Kone-Paut I, Chabrol B, Sampol J, DignatGeorge F. Circulating endothelial cells in Behçet's disease with cerebral thrombophlebitis. Thromb Haemost. (2000) 83:631-2. doi: 10.1055/s-0037-1613881

42. Bozkirli ED, Keşkek SÖ, Kozanoglu I, Yücel AE. High levels of endothelial progenitor cells can be associated with thrombosis in patients with Behçet's disease. Clin Exp Rheumatol. (2014) 32(4 Suppl. 84):S49-53.

43. Andreou I, Tousoulis D, Tentolouris C, Antoniades C, Stefanadis C. Potential role of endothelial progenitor cells in the pathophysiology of heart failure: clinical implications and perspectives. Atherosclerosis. (2006) 189:247-54. doi: 10.1016/j.atherosclerosis.2006.06.021

44. Yao EH, Yu Y, Fukuda N. Oxidative stress on progenitor and stem cells in cardiovascular diseases. Curr Pharm Biotechnol. (2006) 7:101-8. doi: $10.2174 / 138920106776597685$

45. Schatteman GC, Hanlon HD, Jiao C, Dodds SG, Christy BA. Blood-derived angioblasts accelerate blood-flow restoration in diabetic mice. J Clin Invest. (2000) 106:571-8. doi: 10.1172/JCI9087

46. Thum T, Fraccarollo D, Schultheiss M, Froese S, Galuppo P, Widder JD, et al. Endothelial nitric oxide synthase uncoupling impairs endothelial progenitor cell mobilization and function in diabetes. Diabetes. (2007) 56:666-74. doi: 10.2337/db06-0699

47. Hung YC, Sava VM, Blagodarsky VA, Hong MY, Huang GS. Protection of tea melanin on hydrazine-induced liver injury. Life Sci. (2003) 72:1061-71. doi: 10.1016/S0024-3205(02)02348-2
48. Urbich C, Knau A, Fichtlscherer S, Walter DH, Brühl T, Potente M, et al. FOXO-dependent expression of the proapoptotic protein Bim: pivotal role for apoptosis signaling in endothelial progenitor cells. FASEB J. (2005) 19:974-6. doi: 10.1096/fj.04-2727fje

49. Thum T, Fraccarollo D, Galuppo P, Tsikas D, Frantz S, Ertl G, et al. Bone marrow molecular alterations after myocardial infarction: impact on endothelial progenitor cells. Cardiovasc Res. (2006) 70:50-60. doi: 10.1016/j.cardiores.2006.01.002

50. Ozyazgan S, Andican G, Erman H, Tuzcu A, Uzun H, Onal B, et al. Relation of protein oxidation parameters and disease activity in patients with Behçet's disease. Clin Lab. (2013) 59:819-25. doi: 10.7754/Clin.Lab.2012.120722

51. Becatti M, Emmi G, Silvestri E, Bruschi G, Ciucciarelli L, Squatrito D, et al. Neutrophil activation promotes fibrinogen oxidation and thrombus formation in Behçet disease. Circulation. (2016) 133:302-11. doi: 10.1161/CIRCULATIONAHA.115.017738

52. He T, Peterson TE, Holmuhamedov EL, Terzic A, Caplice NM, Oberley LW, et al. Human endothelial progenitor cells tolerate oxidative stress due to intrinsically high expression of manganese superoxide dismutase. Arterioscler Thromb Vasc Biol. (2004) 24:2021-7. doi: 10.1161/01.ATV.0000142810.27849.8f

53. Galasso G, Schiekofer S, Sato K, Shibata R, Handy DE, Ouchi N, et al. Impaired angiogenesis in glutathione peroxidase-1-deficient mice is associated with endothelial progenitor cell dysfunction. Circ Res. (2006) 98:254-61. doi: 10.1161/01.RES.0000200740.57764.52

54. Samman Tahhan A, Hammadah M, Raad M, Almuwaqqat Z, Alkhoder A, Sandesara PB, et al. Progenitor cells and clinical outcomes in patients with acute coronary syndromes. Circ Res. (2018) 122:1565-75. doi: 10.1161/CIRCRESAHA.118.312821

55. Xu Q. The impact of progenitor cells in atherosclerosis. Nat Clin Pract Cardiovasc Med. (2006) 3:94-101. doi: 10.1038/ncpcardio0396

56. Seyahi E, Ugurlu S, Cumali R, Balci H, Ozdemir O, Melikoglu M, et al. Atherosclerosis in Behçet's syndrome. Semin Arthritis Rheum. (2008) 38:1-12. doi: 10.1016/j.semarthrit.2007.09.009

57. Alessio AM, Beltrame MP, Nascimento MC, Vicente CP, de Godoy JA, Silva JC, et al. Circulating progenitor and mature endothelial cells in deep vein thrombosis. Int J Med Sci. (2013) 10:1746-54. doi: 10.7150/ijms.6887

58. Sung SH, Wu TC, Chen JS, Chen YH, Huang PH, Lin SJ, et al. Reduced number and impaired function of circulating endothelial progenitor cells in patients with abdominal aortic aneurysm. Int J Cardiol. (2013) 168:1070-7. doi: 10.1016/j.ijcard.2012.11.002

59. Kim YW, Byzova TV. Oxidative stress in angiogenesis and vascular disease. Blood. (2014) 123:625-31. doi: 10.1182/blood-2013-09-512749

Conflict of Interest: The authors declare that the research was conducted in the absence of any commercial or financial relationships that could be construed as a potential conflict of interest.

Copyright (c) 2019 Emmi, Mannucci, Argento, Silvestri, Vaglio, Bettiol, Fanelli, Stefani, Taddei, Prisco, Fiorillo and Becatti. This is an open-access article distributed under the terms of the Creative Commons Attribution License (CC BY). The use, distribution or reproduction in other forums is permitted, provided the original author(s) and the copyright owner(s) are credited and that the original publication in this journal is cited, in accordance with accepted academic practice. No use, distribution or reproduction is permitted which does not comply with these terms. 